\title{
Dias em desalinho: a ficcionalização do diário em Os guarda-chuvas cintilantes, de Teolinda Gersão
}

\author{
Roberta Guimarães Franco \\ (Universidade Federal Fluminense)
}

\section{RESUMO}

Este artigo pretende analisar a ficcionalização do gênero diário no livro $O s$ guarda-chuvas cintilantes (1984), de Teolinda Gersão. Pretendemos, ainda, observar as aproximações entre a criação estética e o processo de espelhamento, bem como a relação entre a escrita e a morte.

PALAVRAS-CHAVE: Teolinda Gersão; diário; criação estética

\section{ABSTRACT}

This article intends to analyze the Diary as a fiction in the book Os guardachuvas cintilantes (1984), of Teolinda Gersão. We also intend to observe the approaches between the esthetic creation and the mirror, and the relation between writing and death.

KEYWORDS: Teolinda Gersão; Diary; aesthetics creation 


\section{Introdução}

Os guarda-chuvas cintilantes, livro de Teolinda Gersão publicado em 1984 na sequência d'O Silêncio (1981) e de Paisagem com Mulher e Mar ao Fundo (1982), se apresenta como um diário - dado encontrado nas segunda e terceira folhas do livro, abaixo do título, como um subtítulo ou uma indicação de gênero literário.

Em entrevista concedida a Inês Pedrosa no ano da publicação do livro, Teolinda Gersão confessou o seu interesse pelo gênero diário, até o momento um interesse como leitora:

Por um lado, tenho uma fascinação pelos diários, sou uma leitora interessadíssima dos diários dos outros, mas por outro lado, sentia uma recusa em fazê-lo. (...) Eu não quero fazer uma escrita intimista. $\mathrm{O}$ intimismo é uma confissão de certos estados de alma, porventura secretos, mas sempre conscientes, e a mim o que me interessa é captar o inconsciente em relâmpago. (PEDROSA, 1984, p. 4)

No entanto, não é somente do gênero diário que este livro fala. As temáticas abordadas por Teolinda Gersão são inúmeras e não seguem uma ordem lógica. $\mathrm{O}$ que encontramos em Os guarda-chuvas cintilantes são bruscos saltos entre um tema e outro. Assim, nos deparamos com uma mulher que sonha com guarda-chuvas, uma casa com crianças, tarefas domésticas, amores, notícias de jornal, crítica literária, cães, etc. Mas, sem sombra de dúvidas, a temática central deste livro é a própria escrita.

Diante de tantos temas, e considerando a escrita como escrita como elemento mais forte da narrativa, podemos dividir o livro em três partes, baseando-nos no narrador, figura controversa do romance, partes não necessariamente sequenciais ou pontuais: num primeiro momento evidenciamos o desejo de escrever, seguido das várias tentativas e dos seus impedimentos; e por fim temos uma decisão final por parte deste narrador, que encontra um caminho mais lúcido para a sua escrita.

\section{A ficcionalização do diário e suas múltiplas vozes}

Como já dissemos, encontramos a palavra "Diário" nas segunda e terceira folhas do livro como um subtítulo ou uma indicação de gênero literário. Se pensarmos em Lejeune (1996) e no seu contrato com o leitor, deveríamos ler o livro de Teolinda Gersão como um diário. Do mesmo modo, a estrutura da obra - ao primeiro olhar - se apresenta com uma divisão datada que mostra o dia da semana seguido do dia do mês: "Domingo, um".

Para Blanchot, o diário "enraíza o movimento de escrever no tempo, na humildade do cotidiano datado e preservado por sua data" (BLANCHOT, 1987, p. 20). No entanto, ao olharmos atentamente para a divisão do romance percebemos que a narrativa é elíptica, não há - entre as cento e cinco entradas datadas - uma sequência cronológica linear e lógica. Assim, depois de "Domingo, um" encontramos "Sábado, três" e "Segunda, catorze", por exemplo.

Diante disso, o que encontramos no livro de Teolinda Gersão é uma ficcionalização do diário. Segundo Rogério Puga, este livro é um diário parodiado, baseando-se no conceito de paródia de Carlos Ceia: "A paródia é a 
deformação de um texto preexistente (...) deforma, censura, imita (criativamente), desenvolve, referencia e não transcreve um texto preexistente (...)" (CEIA apud PUGA, 2005, p. 507). Assim, o que Teolinda Gersão faz é deformar ou imitar criativamente um gênero literário preexistente, colocando em seu livro uma personagem que deseja escrever.

A primeira referência que encontramos no romance sobre a escrita, e sobre uma voz narrativa que escreve, está na página doze: "A História começa onde começa a escrita (a história começa onde começa a escrita), escrevo no cimo da folha de papel. Antes, é apenas um tempo informe e sem medida" (GERSÃO, 1984, p. 12). Neste trecho evidenciamos a primeira tentativa da escrita, na qual ainda reside a dúvida (e por isso a repetição da frase entre parênteses) entre a "História", grafada como a ciência ou disciplina, e a "história", aquela do cotidiano, a particular. Ainda no mesmo trecho percebemos que, para aquele que escreve, o tempo passa a ter forma, medida. Aquele que escreve um diário, com suas passagens datadas, tenta controlar, medir o tempo.

Sabemos que há alguém iniciando uma tentativa de escrita e chegamos à conclusão de que o resultado desta tentativa seria um diário. $\mathrm{O}$ próprio romance, através de uma personagem, o "crítico", além de nos dar uma definição para o gênero diário, afirma não ser essa a classificação aplicável ao livro em questão. Assim, a própria narrativa discute o gênero do livro de Teolinda Gersão, mas também a tentativa de escrita da personagem:

Não é um diário, disse o crítico, porque não é um registo do que sucedeu em cada dia. Carecendo portanto da característica determinante de um género ou subgénero em que uma obra pretende situar-se, a referida obra está à partida excluída da forma específica em que declara incluir-se. Dixi” (GERSÃO, 1984, p. 20)

Nesse sentido, o romance se apresenta como uma constante desconstrução. Seja pela questão do gênero literário, seja pelos temas que apresenta, Os guarda-chuvas cintilantes está repleto de fragmentação e descontinuidade. Tal questão também é evidenciada ao observarmos as vozes narrativas do romance, já ao longo do livro fica a dúvida quanto à identidade do narrador: quem escreve afinal este "diário"?

No início do romance, logo na primeira entrada, datada "Domingo, um", nos deparamos com uma vOz narrativa em terceira pessoa, exterior à história, que fala de uma personagem feminina e de guarda-chuvas: "Num sonho ela roubava guarda-chuvas (...)" (GERSÃO, 1984, p. 7). No entanto, na segunda página da narrativa - ainda em "Domingo, um" - as pessoas verbais mudam. Em um mesmo parágrafo, que se inicia com o verbo em terceira pessoa "Avançou", encontramos, a partir da terceira linha, todos os verbos e pronomes possessivos em primeira pessoa, e ainda um pronome pessoal "eu", definindo a voz narrativa.

Essa alternância continuará ao longo do romance, confundindo o leitor não somente pela utilização dos verbos em terceira ou primeira pessoa, mas também por encontrar em alguns momentos uma indefinição com relação à temática. A identidade daquele que narra com o "ela" que pratica as ações começa a se confundir, e o narrador parece já não estar tão afastado da narrativa. As emoções de um narrador que, em um primeiro momento, parecia onisciente, nos fazem repensar quem é essa voz: 
A mulher que mora nesta casa começou a escrever um livro, penso, e não sei se essa ideia é uma constatação ou um suspiro. Como se algo irreversível, irremediável, há muito suspenso, desabasse sobre mim, ou como se eu caísse em alguma coisa sobre a qual estivera muito tempo suspensa.(...)

Dever-se-ia levar para todo o lado a mesa onde se escreve, decido. Mas na minha vida é sempre tudo transitório, e esta mesa não durará talvez mais do que um livro. (GERSÃO, 1984, p. 14)

No trecho acima, percebemos claramente o envolvimento do narrador com a ação da mulher que começou a escrever um livro. Essa idéia o perturba, como uma decisão há muito adiada e que agora se impõe. Afinal, chegamos à conclusão de que "eu" e "ela" são a mesma pessoa, e quem narra desdobra-se "continuamente em sujeito que descreve e em objecto que é descrito" (MAGALHÃES, 1987, p. 393).

Trata-se pois de uma narradora única, que se desconstrói e reconstrói na tentativa de encontrar o caminho 'certo' da sua escrita. Ao tentar escrever, principalmente tratando-se de um diário, fica a dúvida de que pessoa usar. Segundo Blanchot: 'Diz-se que o escritor renuncia a dizer 'Eu'. Kafka observa, com surpresa, com um prazer encantado, que entrou na literatura no momento em que pôde substituir o 'Eu' pelo 'Ele"' (BLANCHOT, 1987, p. 17). No caso de nossa narradora, esse momento de substituição ainda está longe, o "eu" ainda se impõe, e incomoda:

"Eu", disse ela, quando eles perderam a paciência de ouvir a história e se foram embora e ela voltou tranquilamente ao nó do problema, recapitulando os dados. Eu, disse, e a palavra era um caroço de ameixa na boca, rolando sobre a língua, mas exterior à superfície, eu, repetiu, e olhou o céu como se fosse um eco, eu ponto de intersecção de pessoas, vidas, tempos, espaços, dimensões, ponto de intersecção de planos, luzes, cores, de sons diferentes. (GERSÃO, 1984, p. 33)

"Eu" multiplica-se, desdobra-se, mas ainda não se transforma em "Ela". Esse conflito ainda é complicado pelo gênero literário escolhido. Os diários, normalmente são escritos em primeira pessoa, mas talvez a necessidade de não se expor a coloque em dúvida, e a terceira pessoa, o "ela", é constantemente convocada. Ou ainda, segundo Blanchot, a primeira pessoa, o "eu", se impõe para fugir do anonimato que é ser "ela":

O "Ele" que toma o lugar do "Eu", eis a solidão que sobrevém ao escritor por intermédio da obra. "Ele" não designa o desinteresse objetivo, o desprendimento criador. "Ele" não glorifica a consciência em um outro que não eu, o impulso de uma vida humana que, no espaço imaginário da obra de arte, conservaria a liberdade de dizer "Eu". "Ele" sou eu convertido em ninguém, outrem que se torna o outro, é que, no lugar onde estou não possa mais dirigir-me a mim e que aquele que se me dirige não diga " $\mathrm{Eu}$, não seja ele mesmo. (BLANCHOT, 1987, p. 18-19). 
Assim, a narradora se mostra e se esconde, mas ainda não consegue chegar a um acordo consigo mesma. Talvez essa seja a maior dificuldade da sua escrita. Ela precisa enfrentar-se para poder enfrentar o papel e a caneta. Ela ainda precisa lidar com as críticas, críticas que envolvem os dois tipos de gênero que a cercam: o gênero diário e o inegável gênero feminino.

Essas questões ficam claras em vários momentos do romance, quando, intercalados ao 'eu' e ao 'ela', encontramos comentários repletos de teorização literária. No entanto, esta teorização ganha uma outra voz, uma voz masculina. A personagem que, na maioria das vezes, é a dona da voz nesses comentários é o professor Pip. Ele é responsável por duras críticas ao gênero diário, gênero que entendemos ser o escolhido pela narradora para a sua tentativa de escrita:

Aquilo que eu olhar existe, o que eu ignorar permanece para sempre no não ser - os diários são profundamente ridículos, diz Pip, que é professor de filosofia, mas secretamente gostaria de ser poeta. $O$ mundo não gira à volta do autor, está-se completamente nas tintas para o autor, o mundo está-se cagando para que Barthes não gostasse de líchias, está-se cagando, cagando, cagando - diários e quejandos são a forma mais ridícula de toda a literatura. (GERSÃO, 1984, p. 24)

É relevante pensarmos o porquê destas passagens terem uma voz masculina. A princípio os diários eram o espaço destinado à escrita feminina, já que as mulheres não tinham autonomia e voz para ocuparem outros espaços, mesmo que literários. Assim, a personagem "Pip" não representa somente a teorização literária, mas também o embate entre o feminino e o masculino. No entanto, esse embate não fica claro no romance, já que não há sequer um diálogo entre Pip e a narradora. Mas as críticas do professor ao gênero diário são implacáveis:

Os diários são perversos, diz Pip. $O$ autor é um ser desconjuntado, a que o olhar do leitor dá uma unidade ilusória - precisar do olho do leitor para existir, para existir frouxamente, virtualmente, numa rápida aparição de três minutos sob um foco de luz, diante de um buraco por onde o leitor voyeur espreita, depois de deitar uma moeda na ranhura da caixa - os diários são a forma mais idiota e mais perversa de toda a literatura. (GERSÃO, 1984, pp. 25-26)

Além de criticar o gênero diário, Pip também faz críticas à literatura de uma forma geral, principalmente ao papel do autor. Para ele a literatura não pode ser vista como um tipo de experiência e o autor é um fraco, já que coloca as suas personagens para viver aquilo que ele não tem coragem. No entanto, ele admite que a autoria também é uma forma de se expor:

As pessoas julgam a literatura um campo adicional de experiência, diz Pip, mas esquecem que é uma experiência apenas virtual, que não pode ser utilizada de modo efectivo. Um autor põe em cena personagens que travam as lutas a que ele próprio se esquiva, fica tranquilamente sentado enquanto as personagens se debatem, em sua vez, uma parte dele expõe-se, enquanto a outra parte fica resguardada em casa, atrás do vidro, com os pés bem quentes diante da lareira. (GERSÃO, 1984, p. 63) 
Há de se levar em consideração e de se colocar em evidência o porquê de um livro que, aparentemente, não trabalha questões de gênero (masculino/feminino) ter uma personagem masculina que assume uma postura extremamente crítica. Além do sexo, também evidenciamos o fato de Pip ser professor, ou seja, além de ser homem, é aquele que detém o saber. Assim, além de comentários metaficcionais, Pip é a oposição clara a uma narradora que ainda se apresenta frágil e cheia de dúvidas e a sua presença coloca ainda mais em evidência a força da temática do processo criativo presente no romance.

\section{Tempo, espelho e morte}

Como já dissemos, a escrita é, sem dúvida, o tema central d'Os guardachuvas cintilantes, e a relação de desejo entre a narradora e o processo da escrita está latente durante toda a narrativa. No entanto, nessa relação existe uma interferência, uma barreira que, na maioria das vezes, parece ser intransponível: o tempo e, mais especificamente, o tempo dedicado à escrita, ao isolamento necessário para a realização deste desejo.

Assim, a duração do tempo é marcada de várias maneiras na narrativa, mas principalmente por essa extrema vontade de escrever e muitas vezes pela impossibilidade de fazê-lo. Então, o tempo psicológico parece ser predominante, já que representa o desejo da narradora de ter mais tempo. No entanto, não há controle sobre tal experiência, o que resulta na sensação de que tudo passa muito rapidamente: "Esse ano demorou-se um só dia, e fugiu que nem um pássaro, pela janela entreaberta” (GERSÃO, 1984, p. 9).

Então, já que o tempo parece não dar tréguas, a narradora tenta de todas as maneiras descobrir um modo de controlá-lo. Então, a escrita do diário nos parece sua primeira tentativa, mas, diante das dificuldades da tarefa, ela crê que a economia é uma forma mais fácil de guardar o tempo:

Nesse dia sobraram-lhe duas horas e ela guardou-as para o dia seguinte. Sempre que calhava fazia assim uma pequena economia, que deixava para utilizar noutra altura em que se visse mais aflita. Era também um modo de adiar envelhecer, adiava sempre, somando essas economias casuais já tinha vários anos na gaveta. Se um dia precisasse, gastá-los-ia de uma vez. Mas secretamente esperava não precisar nunca. (GERSÃO, 1984, p. 11)

No entanto, mesmo fazendo essas pequenas economias e rezando para não precisar usá-las, a narradora confessa que, além de precisar do tempo para a escrita, também tenta controlá-lo para permanecer viva. Confessa também que nunca foi muito boa com suas tentativas de contabilidade e o gênero escolhido por ela para a escrita, o diário, necessita desse controle:

A pequena escrita cotidiana, deixar um risco no tempo, um traço na areia, para provar que estou viva - segunda, terça, quinta, dois, cinco, sete, vinte e quatro, essa obrigação, ou evasão, minuciosa, essa contabilidade estática, passiva, aplicada, metódica, monótona, escolar - oh céus, tive sempre tão pouco a ver com isso, errei sempre na vida as contas todas - mas de onde vem esta íntima convicção de acertar, apesar de tudo, o problema? (GERSÃO, 1984, p. 23) 
É também nesta tentativa de segurar o tempo que evidenciamos mais uma vez a questão do gênero feminino nesta obra. A casa aparece em vários momentos da narrativa, com vários significados distintos. No entanto, a significação mais relevante é a do ambiente que encerra a mulher, que a prende, a ocupa e, principalmente, a impede de escrever. As tarefas domésticas ocupam o tão precioso 'tempo', o tempo da escrita:

O meu problema é muito complicado, explico a mim própria, para ver se entendo. Escrevo pouco desde logo porque não me sento nunca ou quase nunca, passo semanas em pé de um lado para o outro, ofegante mas sem parar de correr. É verdade que as folhas de papel e a caneta me passam pelas mãos, mas não consigo prendê-las porque tenho sempre as mãos ocupadas com outras coisas, panos de cozinha, lençóis, livros, legumes, detergentes, vassouras, há uma infindável multidão de coisas que se intrometem entre a minha mão a caneta e o papel (...) (GERSÃO, 1984, p. 83)

Mas apesar dessa falta de controle do tempo, e de todas as tarefas que a impedem de escrever, a narradora continua em sua tentativa, travando uma luta contra o tempo e fazendo da folha de papel e da sua escrita um espelho. Espelho que a multiplica e a ajuda a enganar o tempo:"Porque há sempre dois lados nas coisas, cada uma é também sempre o contrário de si própria" (GERSÃO, 1984, p. 12).

Desde o início do livro, mais precisamente desde a sua epígrafe "Tudo o que percebemos clara e distintamente é verdadeiro" (Spinoza, Ética) -, encontramos uma referência ao conceito de 'verdade' que, segundo o trecho utilizado por Teolinda Gersão, depende do seu destinatário, ou seja, a 'verdade' depende do ponto de vista daquele que a encara. Assim, para Umberto Eco também existe uma relação entre a imagem que o espelho produz e a verdade, já que a imagem é um reflexo:

Tendo apurado que o que percebemos (diante do espelho) é uma imagem especular, partimos sempre do princípio de que o espelho 'diga a verdade' (...) Ele não traduz. Registra aquilo que o atinge da forma como o atinge. (...) o espelho não interpreta os objetos. (ECO, 1989, p. 17)

No entanto, no romance em questão não é a relação com a verdade que nos interessa ao tratarmos do espelho. Mais do que uma imagem verdadeira, ou até mesmo autêntica, o espelho pode produzir uma imagem de nós mesmos que não conhecemos, o reflexo pode ser entendido como a imagem que os outros veem de nós. Ainda segundo Umberto Eco:

A magia dos espelhos consiste no fato de que sua extensividade-intrusividade não somente nos permite olhar melhor o mundo mas também ver-nos como nos vêem os outros: trata-se de uma experiência única, e a espécie humana não conhece outras semelhantes. (ECO, 1989, p. 18)

Essa duplicidade que o espelho proporciona, tanto de nos vermos duplicados, mas também de termos uma dupla visão de nós mesmos (a nossa e a dos outros), também pode ser comparada ao efeito da escrita. Ao escrever, o 
autor se duplica, colocando nas folhas um eu, que também já é outro. Esse tipo de comparação não é fruto somente de uma interpretação do romance de Teolinda Gersão, mas está explícito nas falas da narradora, que ao escrever tenta ultrapassar essa barreira entre o eu e o outro que se reflete nas páginas de sua escrita. Mais uma vez é o desdobramento entre o sujeito e o objeto, que na verdade são o mesmo:

A página como espelho, reflexo, separação e obstáculo, entre um sujeito e o seu objecto - ela tentava atravessá-la, escrevendo, furá-la com o aparo fino da caneta e agarrar do outro lado o seu rosto. (...)

Media-se apenas, escrevendo, a distância entre o eu e o seu duplo, a sua sombra fugidia, que sempre de novo lhe escapava. (GERSÃO, 1984, p. 34)

Aqui também justificamos a constante alternância entre a primeira e a terceira pessoa como voz narrativa do romance. A duplicidade, causada tanto pela escrita como pelo espelho, causa a duplicidade das vozes. Assim, segundo Umberto Eco, ao nos posicionarmos em frente a um espelho nos dividimos em dois e a imagem refletida é a terceira pessoa, o "ela":

Se as imagens do espelho tivessem que ser comparadas às palavras, essas seriam iguais aos pronomes pessoais: como o pronome eu, que se eu mesmo o pronuncio quer dizer 'mim', e se uma outra pessoa o pronuncia quer dizer aquele outro. (ECO, 1989, p. 21)

Assim, a escrita d'Os guarda-chuvas cintilantes fica dividida entre um duplo, um jogo que esconde e mostra, que engana e revela. No entanto, a narrativa não apresenta somente este jogo de alternância das vozes narrativas, mas também um jogo entre vida e morte, no qual a escrita, a linguagem, é a peça principal. Segundo Foucault (2006), falar para não morrer é uma prática tão antiga como a própria palavra, e ainda há nessa relação entre a linguagem e a morte mais um tipo de espelhamento:

O infortúnio inumerável, dom ruidoso dos deuses, marca o ponto onde começa a linguagem; mas o limite da morte abre diante da linguagem, ou melhor, nela, um espaço infinito (...) A linguagem, sobre a linha da morte, se reflete: ela encontra nela um espelho; e para deter essa morte que vai detê-la não há senão um poder: o de fazer nascer em si mesma sua própria imagem em um jogo de espelhos que não tem limites. (FOUCAULT, 2006, p. 48)

Outra questão apontada por Foucault é a da finitude do homem. A única certeza que todos têm durante a vida é a da chegada da morte. Assim, a linguagem também faria parte da tentativa de se aproximar do que seria a morte, e consequentemente a literatura seria a experiência mais próxima do morrer:

Do interior da linguagem experimentada e percorrida como linguagem, no jogo de suas possibilidades estiradas até seu ponto extremo, o que se anuncia é que o homem é 'finito' e 
que, alcançando o ápice de toda palavra possível, não é ao coração de si mesmo que ele chega, mas às margens do que o limita: nesta região onde ronda a morte, onde o pensamento se extingue, onde a promessa de origem recua indefinidamente...[a literatura se dá como experiência:] como experiência da morte (e no elemento da morte), do pensamento impensável (e na sua presença inacessível), da repetição (da inocência originária, sempre lá, no extremo mais próximo da linguagem e sempre o mais afastado); como experiência da finitude (apreendida na abertura e na coerção dessa finitude). (FOUCAULT, 1987, pp 400-401)

Diante da certeza da finitude, da sua finitude, e da ação irremediável do tempo, a narradora d'Os guarda-chuvas cintilantes prepara estratégias para burlar o esquecimento consequente da morte. Já que após a morte definitiva não poderia mais ter suas pequenas mortes através da escrita, ela resolve deixar vários retratos (mais um tipo de espelhamento e multiplicação), para que com o passar do tempo após a morte eles pudessem continuar contando suas histórias. A narradora, no seu íntimo, busca a imortalidade. Assim, seria como se sua vida pudesse retornar as páginas, os retratos seriam um tipo de diário pós-morte:

Iria pintando em cada dia o seu retrato, decidiu, deixaria retratos sucessivos no tempo, multiplicando-se para aumentar as suas hipóteses de escapar à morte. Porque a morte levaria muito mais tempo a apagar todos esses eus do que apenas um só.

E quando ela estivesse morta e não escrevesse ficariam pelo menos os retratos dela escrevendo, e seria como se a vida que ela escrevia pudesse continuar a voltar as páginas. (GERSÃO, 1984, p. 28)

Essas figurações da morte nos levam à questão da subjetividade no texto contemporâneo, de maneira que os procedimentos estéticos adotados acabam por encenar essa subjetividade, já que pensam sua própria elaboração. Para Blanchot a relação entre a escrita e a morte parte do reconhecimento da segunda por parte do escritor. Sabemos que não há como impedir a morte real, mas no espaço literário é necessário que se imponha diante da morte para que a escrita seja soberana:

(...) não se pode escrever se não se permanece senhor de si perante a morte, se não se estabeleceram com ela relações de soberania. Se ela for aquilo diante do qual se perde o controle, aquilo que não se pode conter, então retira as palavras de sob a caneta, corta a fala; o escritor não escreve mais, ele grita, um grito inábil, confuso, que ninguém entende ou não comove ninguém. (BLANCHOT, 1987, p. 87)

No entanto, escrever é também vivenciar a morte. A cada escrita morre-se um pouco, para ser já outro. É um jogo no qual se pode morrer, mas também adiar a morte. Blanchot deixa muito clara essa idéia do jogo, no qual se brinca com a morte: "Talvez a arte exija que se brinque com a morte, talvez 
introduza um jogo, um pouco de jogo, onde já não existe mais recurso nem controle" (BLANCHOT, 1987, p. 89).

No romance de Teolinda Gersão essa idéia do jogo com a morte também fica evidente. Diante de tantas impossibilidades nas tentativas de escrita, a possibilidade da morte através da escrita parece aceitável para a narradora. Se for necessário entrar em um jogo que leve à morte para conseguir escrever, a narradora d'Os guarda-chuvas cintilantes está pronta para jogar:

Ou é um jogo então, a escrita, admito que é apenas um jogo, concluiu. Mas como qualquer jogo podia levar à morte. Porque o que conferia ao jogo a tensão e o risco, era que, no limite, o jogador encontrava sempre a morte. (GERSÃO, 1984, p. 97)

Desse modo encontramos durante a narrativa de Teolinda Gersão as reflexões de Blanchot sobre a escrita e a morte. Segundo o teórico francês o espaço literário permite a morte, espaço onde está a obra sempre por vir. E o escritor escreve para morrer e a sua obra é, na verdade, o meio e o fim para encontrar a morte:

O escritor é então aquele que escreve para morrer e é aquele que recebe o seu poder de escrever de uma relação antecipada com a morte. (...) a própria obra é uma experiência da morte da qual parece ser imprescindível dispor previamente a fim de se chegar à obra e, pela obra, à morte. (BLANCHOT, 1987, p. 90)

Assim, encontramos no romance em questão duas possibilidades de relação entre a escrita e a morte: uma que imortaliza aquele que escreve, por isso a tentativa da narradora de se perpetuar através de retratos (que seriam um tipo de escrita) e a outra que significa morrer na escrita, morrer a cada escrita. Escrever pode ser a salvação da morte, mas também é vivenciá-la:

E então tudo se transforma em escrita: o amor, o tempo, os dias, o rosto dos que amamos, o próprio corpo, o próprio ar. Perder a vida, para viver apenas em função da escrita. Viver já morto, e ser um texto. Apenas texto. (GERSÃO, 1984, p. 68)

\section{Conclusão}

Sabemos que ainda haveria muito a ser comentado sobre o romance de Teolinda Gersão. No entanto, procuramos focalizar as imagens da narrativa que faziam referência ao processo criativo, ao trabalho da escrita. Assim, a questão do gênero literário diário que não nos indica o gênero do livro $O s$ guarda-chuvas cintilantes, mas sim o gênero pretendido pela narradora criada por Teolinda Gersão.

Logo, desde o início da narrativa identificamos que a temática central do romance era a tentativa de escrita dessa narradora. Assim, procuramos mostrar as suas dificuldades em se transpor para o papel, demonstrada pela alternância entre os pronomes "eu" e "ela". Do mesmo modo atentamos para a sua luta contra o tempo, aquele que não é controlável e que atrapalha o seu processo de escrita.

Como a narradora de Teolinda Gersão tenta escrever um livro, procuramos abordar na nossa leitura os elementos textuais que apontavam para 
o processo de criação, como o espelhamento, através do qual a personagemnarradora-escritora multiplica-se, tornando-se "eu" e "ela". A página como um espelho, capaz que refletir já um outro, e não o "eu" que conhecemos. Seguindo as idéias de Blanchot identificamos ainda no texto as possibilidades de relação entre o processo de escrita e a morte.

Assim, procuramos dar ênfase aos elementos que apontavam para a tentativa de escrita da narradora d'Os guarda-chuvas cintilantes. A dificuldade da narradora diante do processo criativo, a dificuldade de estabelecer a sua identidade diante da própria escrita: mulher, escritora, dona de casa.

\section{REFERÊNCIAS BIBLIOGRÁFICAS}

ECO, Umberto. Sobre espelhos e outros ensaios. Rio de Janeiro: Nova Fronteira, 1989.

FOUCAULT, Michel. As palavras e as coisas: uma arqueologia das ciências humanas. São Paulo: Martins Fontes, 1987.

Ditos e escritos III - Estética: literatura e pintura, música e cinema. Rio de Janeiro: Forense Universitária, 2006.

GERSÃO, Teolinda. Os guarda-chuvas cintilantes. Lisboa: O jornal, 1984.

Dezp perguntas a Teolinda Gersão. In: Seixo Review, Revista Semestral de Artes e Letras. Disponível em: http://www3.telus.net/eduardo-b-pinto/ teolindagersao entrevista.htm. Acesso em 30 de novembro de 2007.

MAGALHÃES, Isabel Allegro. O tempo das mulheres: a dimensão temporal na escrita feminina contemporânea. Lisboa: Imprensa Nacional - Casa da Moeda, 1987.

PEDROSA, Inês. Entrevista Teolinda Gersão: interessa-me captar o inconsciente em relâmpago. In: Jornal de Letras, Artes e Idéias, ano $4, \mathrm{n}^{\circ}$ 103, 26/06/1984.

PUGA, Rogério Miguel. Os guarda-chuvas cintilantes: o diário ficcional de Teolinda Gersão e o romance diário. In: FERNANDES, Maria da Penha Campos (coord.). História(s) da literatura (actas do $1^{\circ}$ Congresso Internacional de Teoria da Literatura e Literaturas Lusófonas). Coimbra: Edições Almedina, 2005, pp. 502-513.

SEIXO, Maria Alzira. Os Guarda-Chuvas Cintilantes: de Teolinda Gersão. In: SEIXO, Maria Alzira. A palavra do romance - ensaios de genologia e análise. Lisboa: Horizonte Universitário, 1986, pp. 237-241. 